\section{CONF-88100) 2}

Tritium pellet injector results *
The semmed memecior hes two witicuont to a centrector of the US Griverninery under convert in. Of

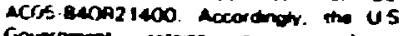

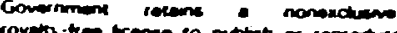

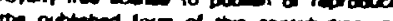

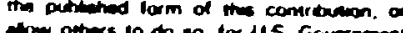
throw other to do so. to US Grvernmens Duroosen

P. W. Fisher, M. L. Bauer, L. R. Baylor, L. E. Deleanu, D. T. Fehling, S. L. Milora, J. C. Whitson

Oak Ridge National Laboratory, Oak Ridge, Tennessee 37831

\title{
ABSTRACT
}

Injection of solid tritium pellets is considered to be the most promising way of fueling fusion reactors. The Tritium Proof-of-Principle (TPOP) experiment has demonstrated the feasibility of forming and accelerating tritium pellets. This injector is based on the pneumatic pipe-gun concept, in which pellets are formed in situ in the barrel and accelerated with high-pressure gas. This injector is ideal for tritium service because there are no moving parts inșide the gun and because no excess tritium is required in the pellet production process. Removal of $3 \mathrm{He}$ from tritium to prevent blocking of the cryopumping action by the noncondensible gas has been demonstrated with a cryogenic separator. Pellet velocities of $1280 \mathrm{~m} / \mathrm{s}$ have been achieved for 4-mm-diam by $4-\mathrm{mm}$-long cylindrical tritium pellets with hydrogen propellant at $6.96 \mathrm{MPa}$ (1000 psi).

\section{INTRODUCTION}

Many types of pellet injectors have been successfully used to produce and accelerate hydrogen and deuterium pellets for fusion experiments. However, no previous attempt has been made to produce tritium pellets. The properties of tritium, especially its radioactive decay, are quite different from those of the other hydrogen isotopes. Decay heating, the production of $3 \mathrm{He}$ and its effect on the physical properties of solid tritium, the need for tritium-compatible materials of

*Research sponsored by the Office of Fusion Energy, U.S. Department of Energy, under contract DE-AC05-840R21400 with Martin Marietta Energy Systems, Inc. 
construction, and use of double containment to prevent tritium release are all problems unique to tritium. Because of these differences, it is desirable to demonstrate the production and acceleration of tritium pellets.

Pneumatic guns produce pellets by direct condensation of hydrogen from the gas phase into the chamber or chambering mechanism of the gun. Because of their simplicity, they appear to be appropriate for initial tritium experiments. Milora and co-workers $1-4$ used a disk-shaped pellet carrier with pellet-size holes ( 1 and $1.6 \mathrm{~mm}$ in diameter) to transport pellets from a fill station to the barrel for firing. Pellets were formed at the fill station by direct condensation from the gas phase. Pellet length in this device was set by the thickness of the disk which sheared off any excess solid as it was rotated. Lafferranderie and co-workers 5 later used an approach in which the pellet was frozen directly in the barrel in a position ready for firing; they referred to this approach as in situ condensation. A pellet-length copper section was sandwiched between two stainless steel flanges in the barrel. Gas admitted from both ends of the barrel was frozen into a pellet ready for firing. This concept simplifies gun operation because it eliminates all moving parts.inside the gun. However, since pellet length is not mechanically constrained, pellet size is more difficult to control. Pellets have a tendency to grow beyond the ends of the cooled section of the barrel. Lafferranderie attached heaters to the stainless steel flanges near the pellet to increase the temperature gradient to the pellet and reduce its length. Combs and co-workers, 6 using a similar cryosat design, also obtained pellets that grew beyond the end of the cooled section of the barrel. Pellet fength in this device was controlled by the temperature of small cryostats attached to the barrel near the pellet. Sorensen and co-workers 7 described a gun in which the barrel was a continuous stainless steel tube; copper cooling rings were 
soldered to the outside of the barrel. The center ring formed the pellet, and the outer rings were used to control pellet length by adjusting their temperature.

At Oak Ridge National Laboratory (ORNL), a pipe gun has been developed for the Tritium Proof-of-Principle (TPOP) experiment. 8 The in situ condensation concept was chosen for this gun because it requires no excess material to produce the pellet and because the gun itself has no moving parts. The need for a tritium-compatible system also led to the use of a continuous stainless steel barrel soldered into a cryostat. This gun differs from previous guns in that pellet size has been successfully controlled without heaters on the barrel. The experiment has been installed and operated with tritium in the Tritium Systems Test Assembly (TSTA) at Los Alamos National Laboratory (LANL).

\section{GUN DESIGN}

Figure 1 shows a diagram of the TPOP gun. It consists of a 4-mm-i.d. stainless steel tube with a wall thickness of $0.4 \mathrm{~mm}(0.016 \mathrm{in}$.), which is silver soldered into a 3-mm-thick copper plate. A goal of this work was to produce right circular cylinder pellets with an aspect ratio of one, i.e., $4 \mathrm{~mm}$ in diameter and $4 \mathrm{~mm}$ long. The cooled section was shorter than the desired pellet length because previous work showed that pellets always grow beyond the end of the cooled region of the barrel.5-7 The joint between the tube and the plate was carefully machined to form a sharp corner by removing excess solder from the barrel. A VCR fitting on each end of the barrel serves to interface the gun with the propellant valve and the vacuum system. Two $1.91-\mathrm{cm}(0.75-\mathrm{in}$.) sleeves are soldered to the barrel on either side of the copper disk; they fit into O-ring sealed flanges in the guard vacuum. The VCR fittings (with male nuts) fit through these seals and facilitate disassembly of the 
gun. The copper piate is bolted onto the liquid heiium (Lhie) cryustat, arlu the interface is coated with silver-loaded grease for good thermal contact. The temperature of the plate is measured by silicon diodes mounted directly on the plate. The temperature is controlled by a heater on the LHe-cooled cryostat. The barrel is $1 \mathrm{~m}$ long from the plate where the pellet is formed to the point of discharge, and the breech section of the barrel is about $14 \mathrm{~cm}$ long. There is a demountable thermal short between the barrel and the guard vacuum flange, the position of which helps control the length of the pellet. The gun barrel and plate assembly can be easily removed from the assembly without disturbing any other gun parts.

The gun cryostat is a $12.7-\mathrm{cm}-0 . \mathrm{d}$. copper block with $0.318-\mathrm{cm}$ square spiral cooling channels machined into it on a $0.635-\mathrm{cm}$ pitch. A $50-\Omega$ Nichrome heater is wrapped and epoxied to the perimeter of the cryostat. The LHe coolant passes through a flow control valve, then through the gun cryostat, and finally through the $3 \mathrm{He}$ separator before it is discharged. The $3 \mathrm{He}$ separation is required during tritium operation because concentrations. of this gas must be extremely low concentrations for good pellet formation. The separator is basically a small copper counter-current heat exchanger with a large internal volume to allow tritium condensation while maintaining low 3He pressure. The entire gun assembly is mounted on a single flange so that it is readily accessible when the guard vacuum enclosure is removed.

Figure 2 shows the gun in the pellet diagnostic line. The propellant valve is a fast solenoid valve with an opening time of $<1 \mathrm{~ms}$, described by Milora and co-workers.9 The valve is all metal except for the stem tip. which is Vespel. High-pressure propellant (hydrogen) is delivered at the desired supply pressure to a 
ORNL.OWG 88.2733A FEO

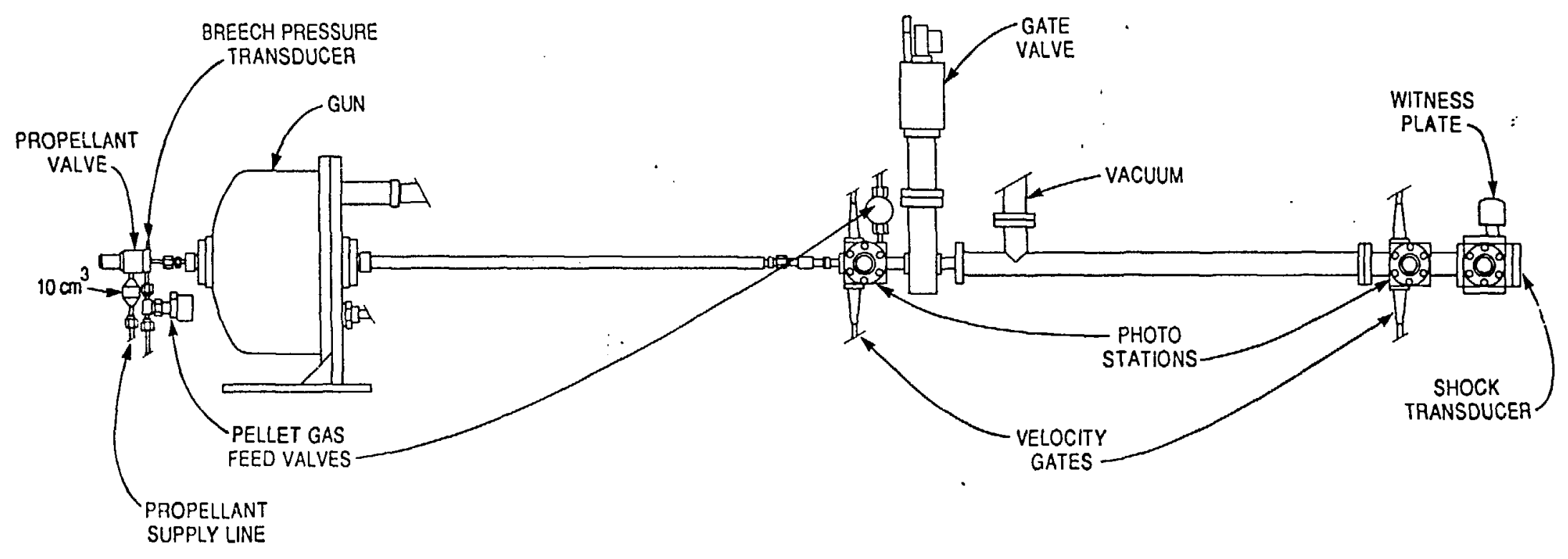

Fig. 2. TPOP gun and pellet diagnostic line. 
10- $\mathrm{cm}^{3}$ cylinder attached directly to the valve body. The valve that delivers gas for pellet formation is attached to a VCR coupling on the front flange of the fast valve. Passages in the fill line fittings and valve were filled vrith stainless steel rod to reduce the excess volume for propellant gas. A transducer to measure the breech pressure is also mounted in the front flange of the fast valve.

The first diagnostic station contains a velocity gate, a photo station, and a pellet gas feed valve. The system was designed for minimum volume to reduce the excess gas required for filling operations involving tritium. The volume of the gun and first diagnostic station with the gate valve, feed valves, and fast valve closed is $88 \mathrm{~cm}^{3}$. The second diagnostic station contains a velocity gate, a photo station, a shock transducer, and a witness plate that can be rotated into or out of the pellet path. A 1.27-cm-o.d. guide tube connects the first and second diagnostic stations.

The velocity gates use $1-\mathrm{mm}$ o.d. quartz optical fibers to form a light beam that, when interrupted, indicates the presence of a pellet. The gate in the first station is located at the end of the barrel. It has two beams located along the pellet flight path a short distance apart. The velocity estimate obtained from these sensors is used to set the time for triggering the flash at the first photo station. The gate at the second station is located just after the guide tube. It has three beams that traverse the pellet flight path. Interruption of any one of these beams indicates the presence of a pellet. This array virtually guarantees that the pellet will be detected, regardless of its position as it leaves the guide tube. The two velocity gates are about $80 \mathrm{~cm}$ apart. The velocity determined between the first and second gates is used to set the time for triggering the flash at the second photo station. After the second velocity gate the pellet travels about $20 \mathrm{~cm}$ before it reaches the end of the pellet line. A shock transducer is located at the end of the line to mark 
the time the pellet strikes the surface. Signols from the light gates and the shock transducers are digitized by a CAMAC system and recorded by a computer. The digitized data are used to calculate three velocities: the first is calculated from the times at which the first and second light gates are tripped, the second from the time at which the first light gate is tripped and the first indication of shock, and the third from the time at which the second light gate is tripped and the first indication of shock. The analog circuit that produces the camera triggers also provides an analog signal proportional to the velocity determined between the two light gates. Pellet images are recorded on a video recorder with a solid-state camera. The image is backlighted by a flash from a pulsed laser.

The gun and pellet line are housed in a glovebox that provides secondary containment for tritium. A versatile feed gas system, also located in the glovebox, supplies tritium to the gun at the desired pressure, carries out the 3 He separation. can mix tritium with other gases, supplies propellant gas to the fast valve, and controls exhaust to the external vacuum system. This sytem is operated remotely through electro-pneumatic and solenoid valves. It uses a $15-\mathrm{m} 3 / \mathrm{h}$ Normetex scroll pump backed by a metal diaphragm pump for vacuum within the process loop. Exhaust from the glovebox is collected by the TSTA vacuum system. TSTA then processes the gas to recover the tritium. More complete descriptions of the process system and the interfaces with TSTA are presented in Ref. 8.

Figure 3 is a block diagram of the TPOP control and data acquisition system. All routine TPOP operations inside the glovebox are controlled by equipment located outside the glovebox. The operator generally works only with the equipment shown in the bottom row of blocks in Fig. 3. Programmed operation of the gas supply and vacuum system is performed with an NCR-PC8 personal computer 


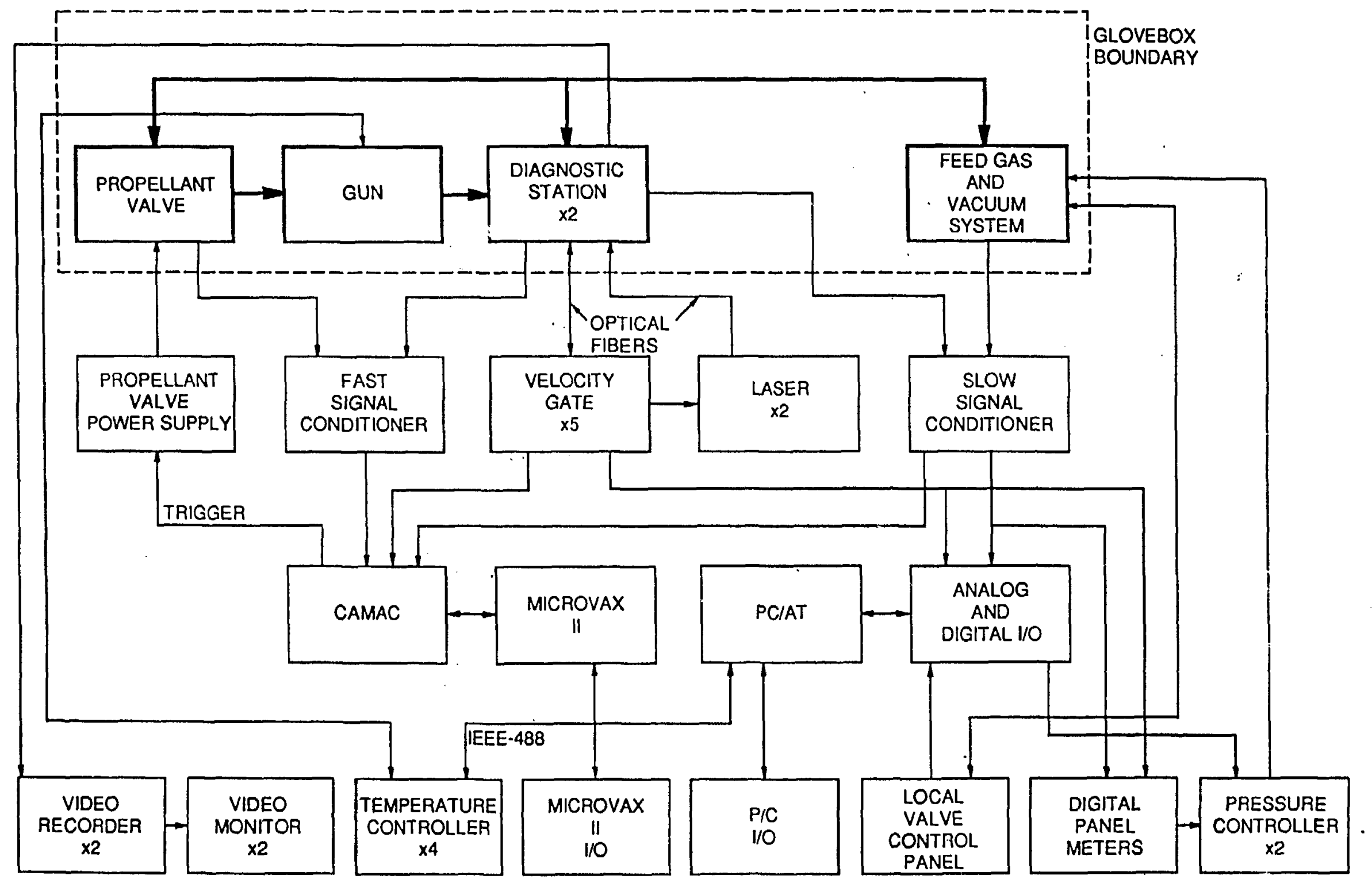

Fig. 3. TPOP control and data acquisition system. 
(PC) using a program named THE FIX developed by tritellution. The pregrar controls all digital and analog input and output operations through an Analog Devices micro-Mac-4000 unit. The PC also operates the Lakeshore DRC-91C cryogenic temperature controllers from THE FIX through the IEEE-488 bus using a program written in C especially for this purpose. THE FIX has been configured to allow the operator to see and control the entire process loop in manual mode from the PC, see and control the gun temperatures, read and trend all analog inputs (temperatures, pressures, etc.), and select the program that is required to run the system. All normal operations, such as tritium transfer to the glovebox, 3 He separation, gun filling, etc., are carried out automatically by these programs. A valve control panel is provided as a manual backup for the computer system. All valves in the glovebox can be operated from this panel. Pressures in the system are controlled by MKS-244/245 pressure control units and valves. The set-point pressures for these controllers come from the computer, and the control-point pressures are patched in from the digital panel meters.

The MicroVAX II computer collects fast transient data from the CAMAC crate, provides the trigger for the fast valve that fires the pellet, and collects a snapshot of all analog data just before each shot. After the runs have been completed, programs are run to plot the transient data, analyze the transient data to determine pellet velocities, and report the pre-trigger analog values. Several hard-wired interlocks have been implemented to prevent inadvertent hazardous occurrences. such as firing the fast valve into a closed system. 


\section{EXPERIMENTAL RESULTS}

The injector initially operated at ORNL, where it was used to produce deuterium pellets. Variables that control pellet size are the pellet cryostat temperature, position of the thermal short on the front of the barrel, fill pressure, and fill direction (i.e., from either or both ends of the barrel). Unless otherwise indicated, the data presented here are for pellets that were allowed to form until equilibrium was reached between the pellet vapor pressure and the feed gas pressure. Equilibrium is defined here as no observerable pressure change for a period of $30 \mathrm{~s}$. When pellets were made by filling from only one direction, they were filled from the breech or rear of the gun. Data from front-filled pellets are not presented because these pellets were generally of a poor quality. Filling from the front apparently leaves voids in the back of the pellet; when these voids are filled with high-pressure gas during acceleration, they tend to fracture or even explode the pellets as they emerge from the barrel into the vacuum.

Figure 4 shows the effect of heat sink location on deuterium pellet size. With no heat sink, there is about a $90-\mathrm{cm}$ conduction path to room temperature through the barrel in front of the pellet. With the heat sink $10 \mathrm{~cm}$ from the pellet, there is about the same temperature gradient on both sides of the pellet. Deuterium pellets that are $4 \mathrm{~mm}$ in diameter by $4 \mathrm{~mm}$ long contain $6.2 \mathrm{kPa}-\mathrm{l}$ ( 47 Torr L) of gas. As can be s:en from the figure, moving the heat sink provides a coarse adjustment of pellet size that can bring the operating curve into the desired range. Figure 5 shows the effect of cryostat temperature and equilibrium fill pressure on pellet size. These are typical of families of operating curves obtained at different heat sink locations. A wide range of pellet sizes can be produced by varying the temperature and pressure according to the curves. Filling the gun from both ends of the barrel 


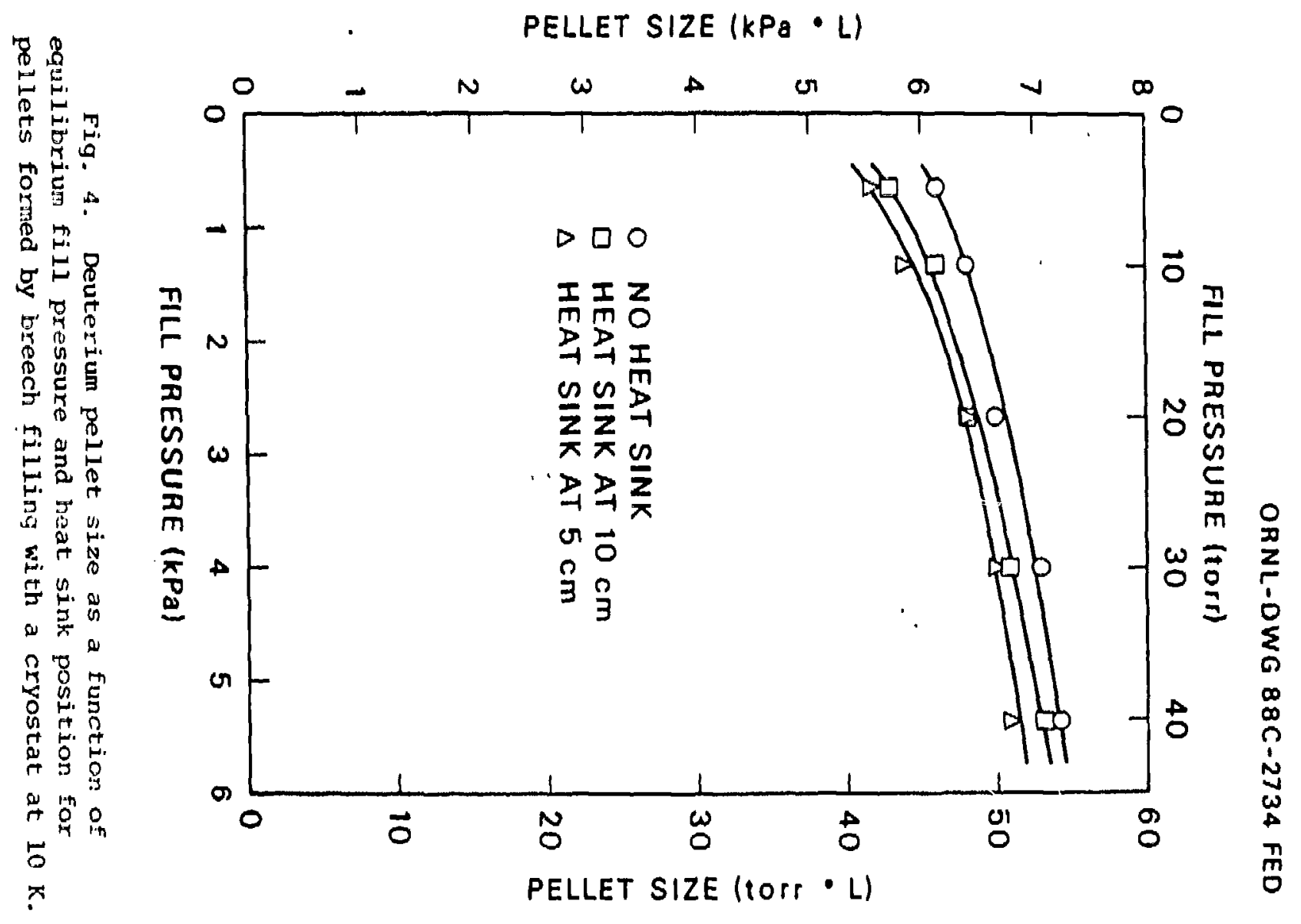




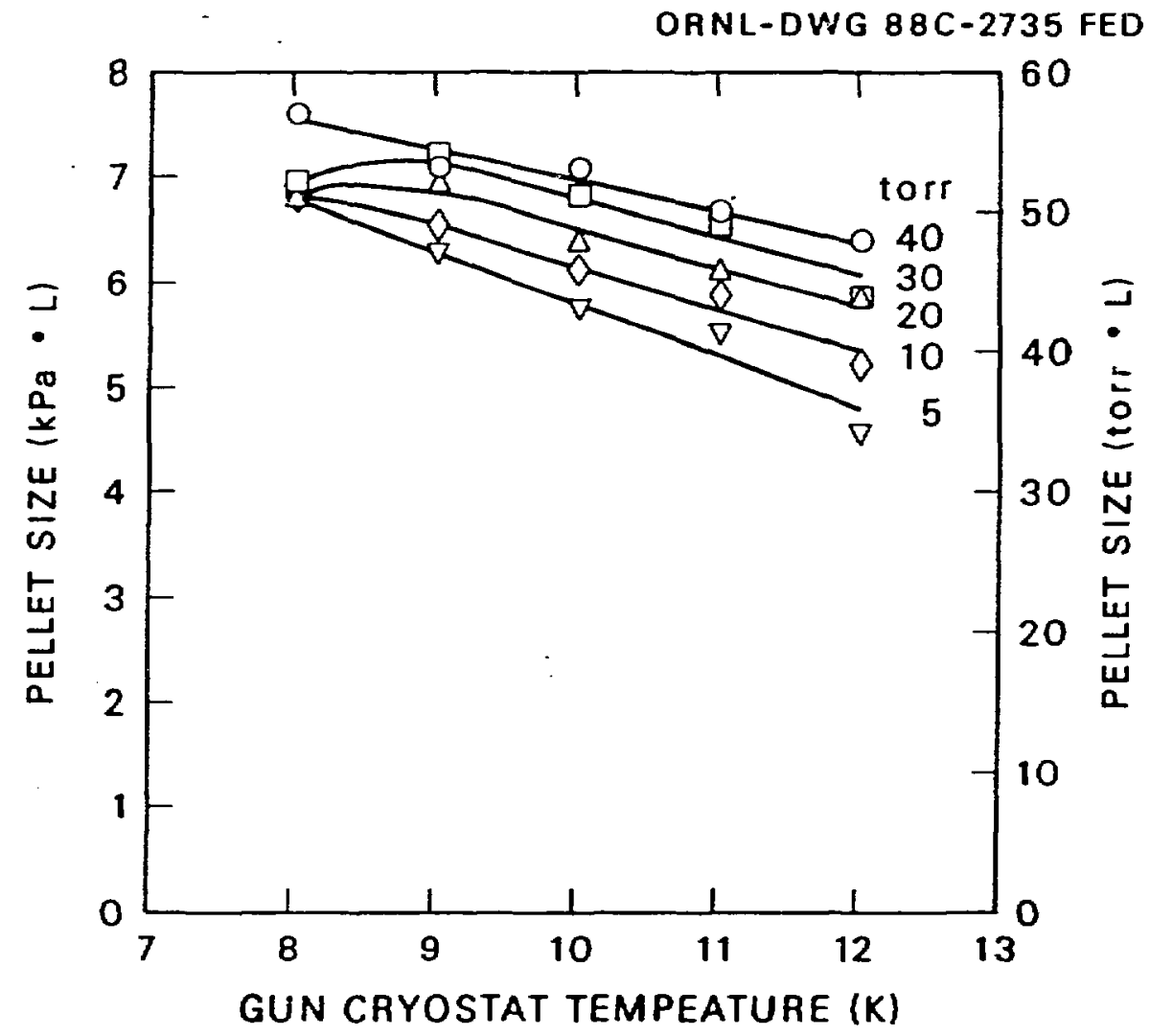

Fig. 5. Deuterium pellet size as a function of temperature and equilibrium fill pressure for pellets formed by breech filling with the cryostat at $10 \mathrm{~K}$. . 
produces pellets that are $15 \%$ to $35 \%$ !arger than those masc by filling from the breech only.

It generally takes on the order of $5 \mathrm{~min}$ to reach equilibrium during pellet formation. Figure 6 shows a typical deuterium filling curve. Figure 7 shows the pellets formed at various points along the curve. Pellets appear to grow radially inward from the 3-mm-long cryostat until closure occurs at tine centerline. Pellets then grow axially with heat transfer occurring through the solid pellet, which apparently has a higher thermal conductivity than the stainless steel barrel. The pellet that is $87 \%$ of equilibrium size at these conditions contains $6.2 \mathrm{kPa}-\mathrm{I}$ ( 47 Torr I) of deuterium and required only $100 \mathrm{~s}$ for formation. Thus, pellets can be formed in short times if nonequilibrium filling procedures are employed.

Figure 8 shows velocities of $6.2-\mathrm{kPa}$ I (47 Torr- 1 ) deuterium pellets as a function of supply pressure. These data agree with those for 4-mm-diam pellets reported by Combs and co-workers. 10 Figure 9 shows photographs of the six highest-velocity pellets. All were produced with equilibrium fills at a pressure of $2.0 \mathrm{kPa}$ (15 Torr), with filling from the breech only, with a cryostat temperature of $10 \mathrm{~K}$, and with the thermal short $5 \mathrm{~cm}$ from the front of the pellet.

Results for tritium are still preliminary since only a very short amount of experimental time has been available at TSTA. Figure 10 shows a typical tritium pellet. This particular pellet contained $6.9 \mathrm{kPa}$ I (52 Torr I) of tritium and had a velocity of $1280 \mathrm{~m} / \mathrm{s}$ with a supply pressure of $6.9 \mathrm{MPa}$ (1000 psi). This is about $85 \%$ of the velocity of deuterium pellets fired at the same supply pressure. If this scale factor persists throughout the velocity vs supply pressure curve, tritium pellet velocities should reach $1500 \mathrm{~m} / \mathrm{s}$ at supply pressures of about $15 \mathrm{MPa}$ (2200 psi). At 


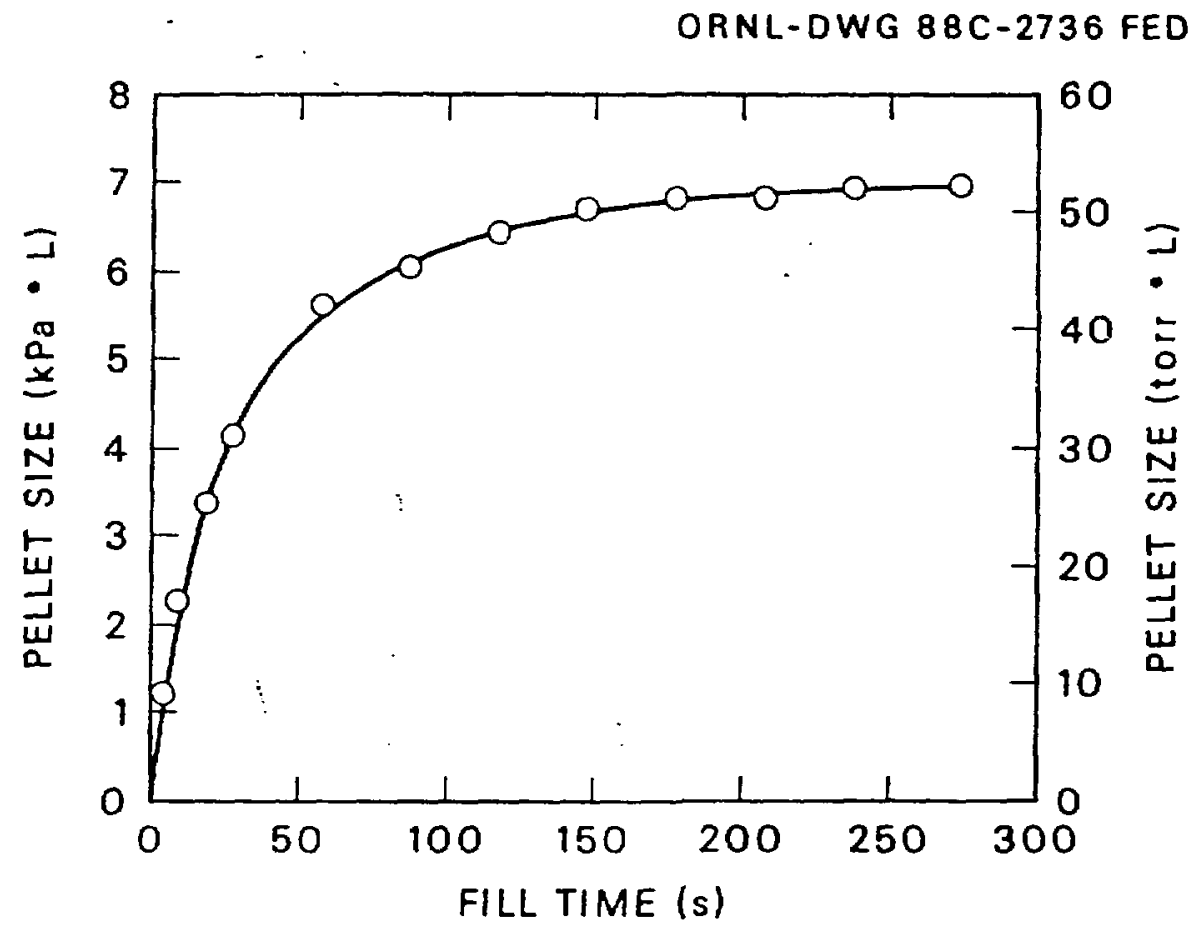

Fig. 6. Deuterium uptake as a function of time for a pellet formed by breech filling with the cryostat at $10 \mathrm{~K}$ and with a fill pressure of $5.3 \mathrm{kPa}$ (40 Torr). 


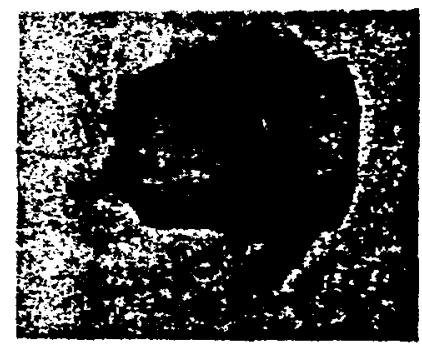

$100 \%$

$280 \mathrm{~s}$

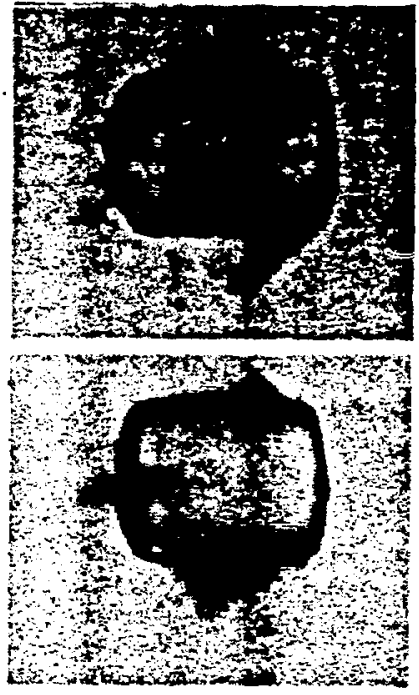

$96 \%$

$200 \mathrm{~s}$

\section{$87 \%$}

$100 \mathrm{~s}$

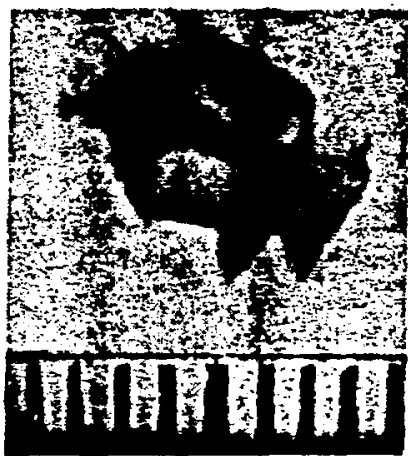

$75 \%$

$50 \mathrm{~s}$

$\mathrm{mm}$ scale

Fig. 7. Deuterium pellets at various stages of formation along the curve shown in Fig. 6.

REPPDDUCED FROM BEST AVALABLE COPY 


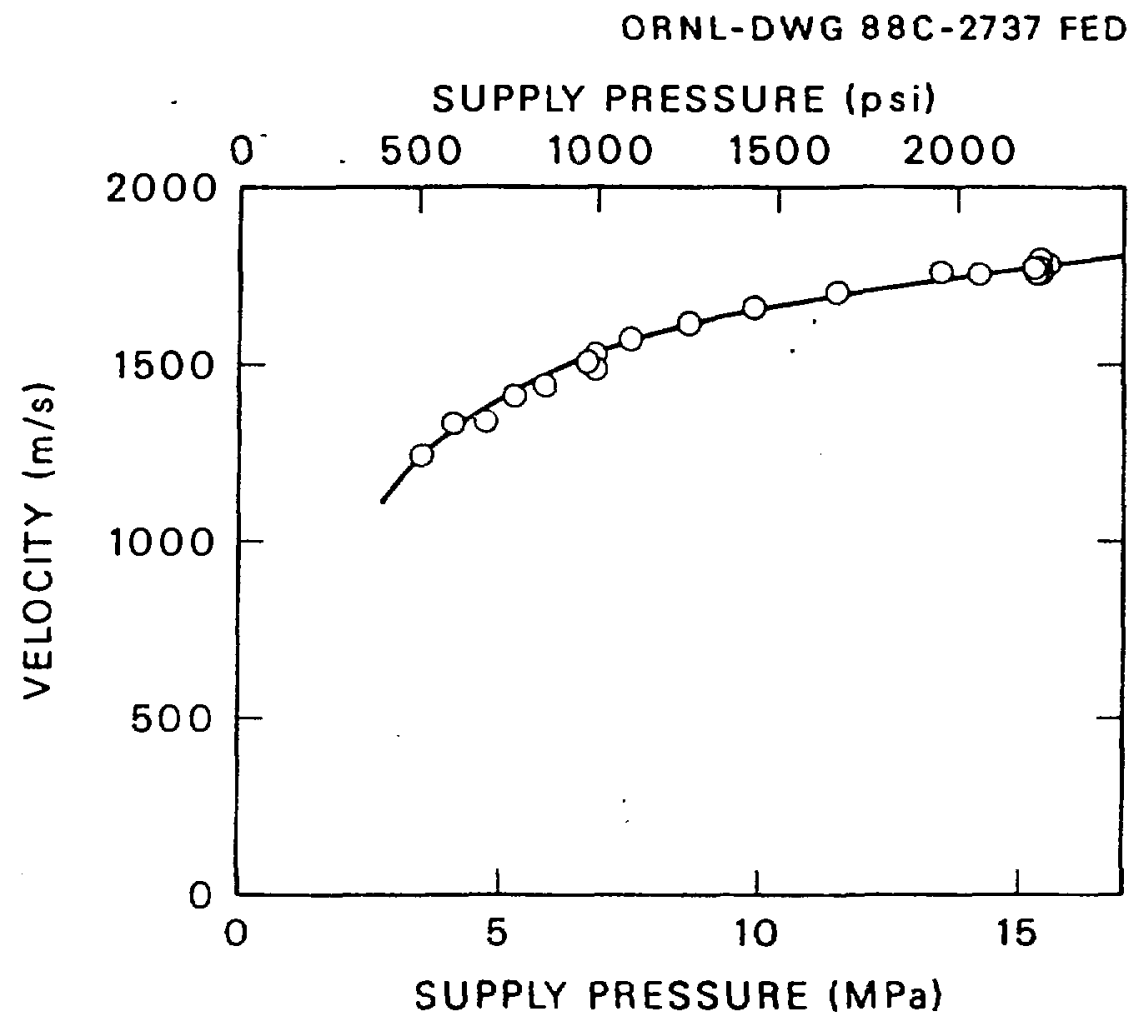

Fig. 8. Velocity of 6.2-kPa-1 (47-Torr 1) deuterium pellets as a function of hydrogen propellant supply pressure. 
FLIGHT DIRECTION
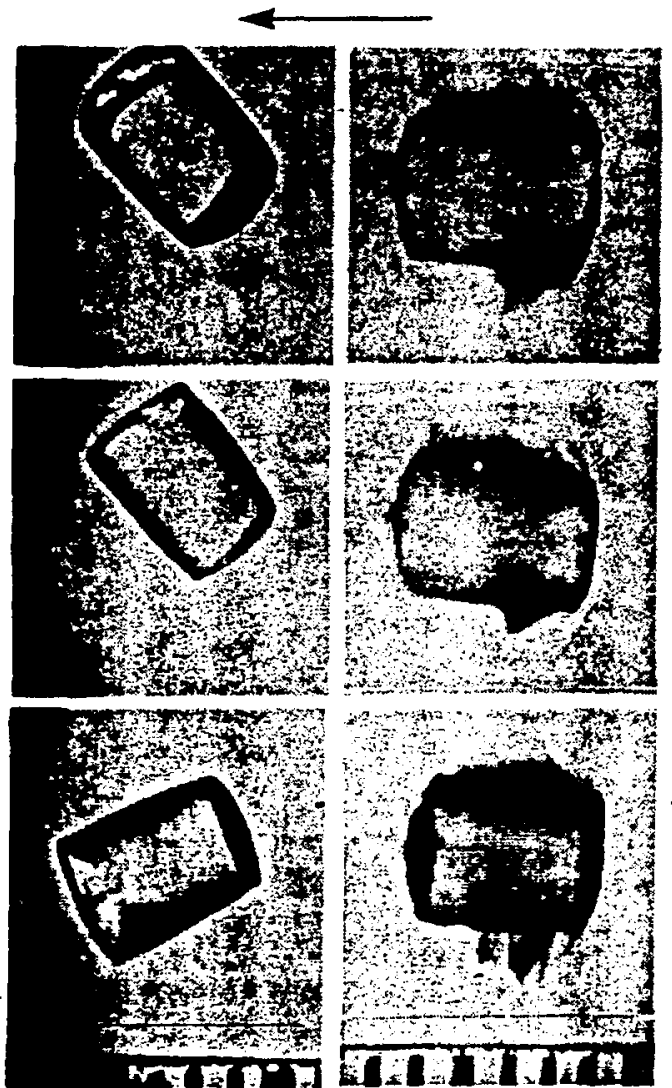

2

PHOTO STATION

\section{FLIGHT DIRECTION}
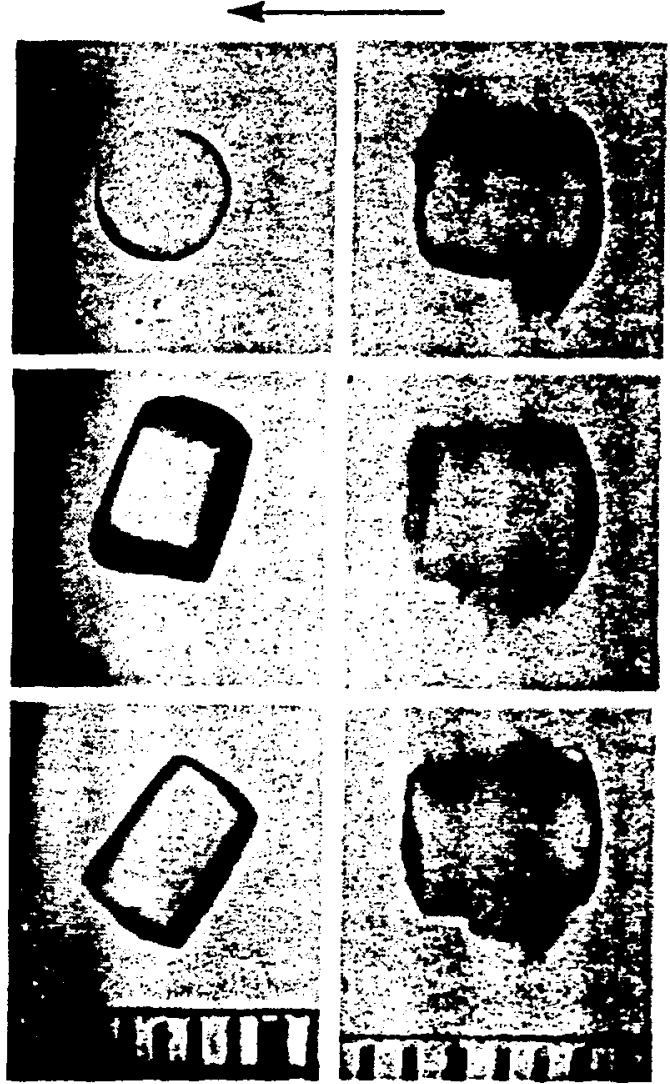

as
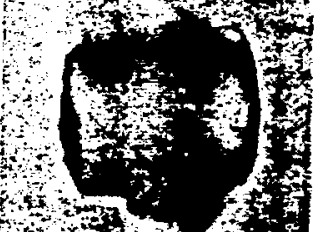

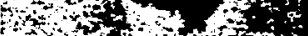

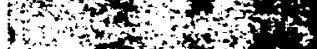

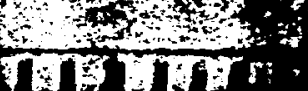

2

PHOTO STATION

Fig. 9. Deuterium pellets with velocities between 1750 and $1790 \mathrm{~m} / \mathrm{s}$. 


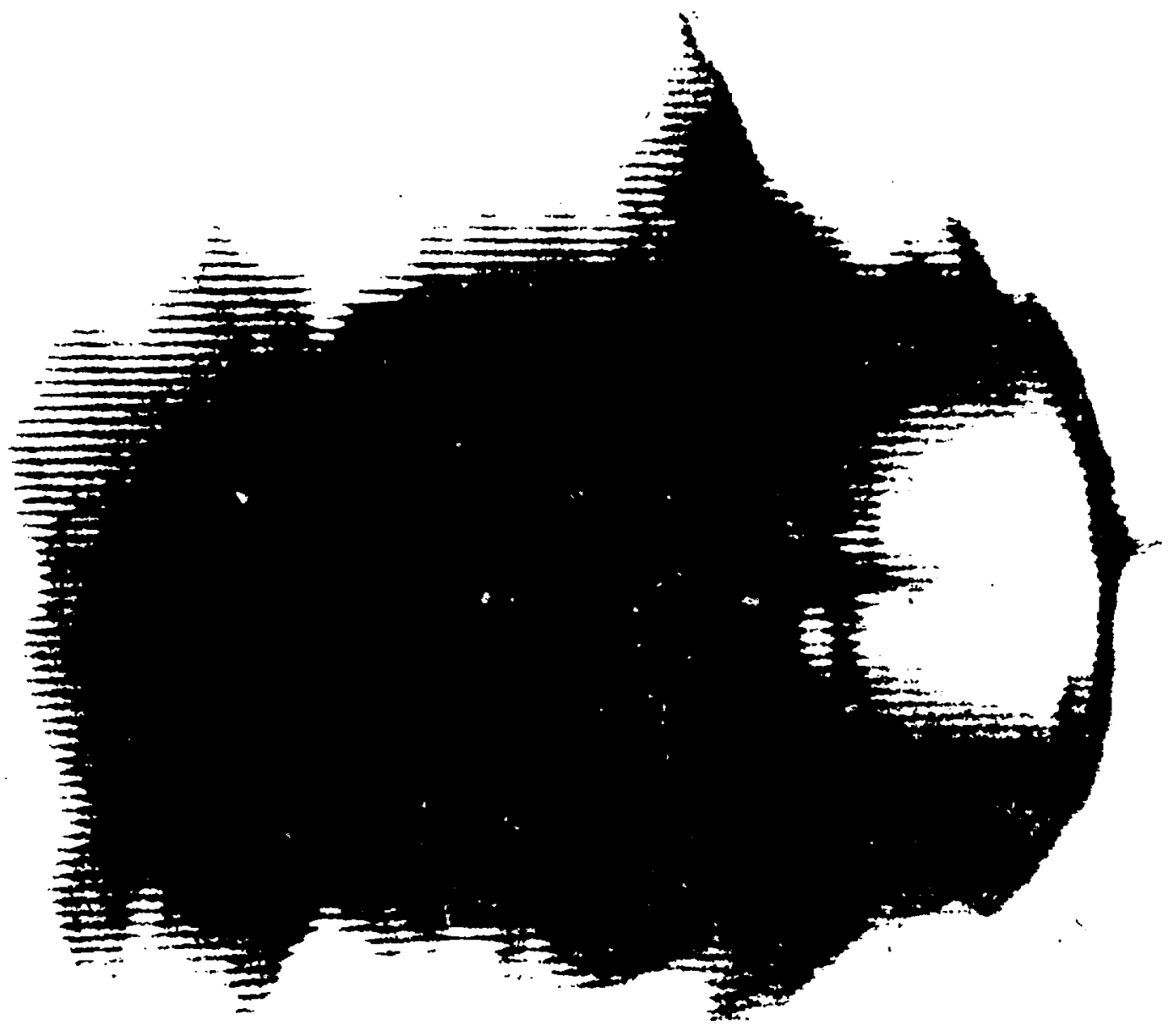

Fig. 10. A tritium pellet.
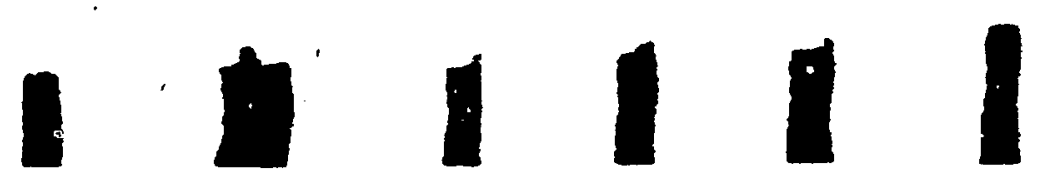

REPRCDUCÉD FROM BEST AVAILAELE COPY 
this writing, about $1 \mathrm{~g}(10,000 \mathrm{Ci})$ of tritium has been processed through the TFOF experiment. Three $3 \mathrm{He}$ separations were made; starting with $13 \% 3 \mathrm{He}$ final concentrations of $0.6 \%, 0.4 \%$, and $0.06 \% 3 \mathrm{He}$ were achieved with different separation procedures. It is expected that even higher degrees of separation will be possible with improved procedures.

\section{CONCLUSION}

A simplified pipe gun pellet injector has been demonstrated to be quite versatile and capable of producing high-quality pellets for fusion experiments. The injector has been used to produce the world's first tritium pellets. These results, although preliminary, indicate that tritium pellet injection is a viable technology that can be used to fuel future fusion reactors. 


\section{REFERENCES}

1. S. L. Milora and C. A. Foster, "Pneumatic Hydrogen Pellet Injector System for the ISX Tokamak," Rev. Sci. Instrum. 50, 482 (1979).

2. S. L. Milora, "Review of Pellet Fueling," J. Fusion Energy 1, 15 (1981).

3. S. L. Milora et al., "Development of Hydrogen Pellet Injectors and Pellet Fueling Experiments at Oak Ridge National Laboratory," in Proceedings of the 9th International Conference on Plasma Physics and Controlled Nuclear Fusion Research, Baltimore, 1982 (International Atomic Energy Agency, 1983), Vol. 2, pp. 461-470.

4. S. K. Combs et al., "Development of Hydrogen Pellet Injectors at ORNL," Nudl. Technol./Fusion 4, 666 (1983).

5. J. Lafferranderie et al., "Experimental Test of 5-mm Diameter $D_{2}$ Pellets Produced by In-Situ Condensation," Fusion Technol. 10, 1367 (1986).

6. S. K. Combs, S. L. Milora, and C. R. Foust, "Simple Pipe Gun for Hydogen Pellet Injection," Rev. Sci. Instrum. 57, 2636 (1986).

7. H. Sorensen et al., "Simplified Pipe Gun," Rev. Sci. Instrum. 58, 2336 (1987).

8. P. W. Fisher et al., "Tritium Proof-of-Principle Injector Experiment," Fusion Technol., accepted for publication.

9. S. L. Milora, S. K. Combs, and C. R. Foust, "Fast-Opening Magnetic Valve for High-Pressure Gas Injection and Applications to Hydrogen Pellet Fueling Systems," Rev. Sci. Instrum. 57, 2356 (1986).

10. S. K. Combs et al., "Repeating Pneumatic Hydrogen Pellet Injector for Plasma Fueling," Rev. Sci. Instrum. 56, 1173 (1985). 


\section{FIGURES}

Fig. 1. Tritium Proof-of-Principle gun.

Fig: 2: TPOP gun and pellet diagnostic line.

Fig. 3. TPOP control and data acquisition system.

Fig. 4. Deuterium pellet.size as a function of equilibrium fill pressure and heat sink position for pellets formed by breech filling with the cryostat at $10 \mathrm{~K}$.

Fig. 5. Deuterium pellet size as a function of temperature and equilibrium fill pressure for pellets formed by breech filling with the cryostat at $10 \mathrm{~K}$.

Fig. 6. Deuterium uptake as a function of time for a pellet formed by breech filling with the cryostat at $10 \mathrm{~K}$ and with a fill pressure of $5.3 \mathrm{kPa}$ (40 Torr).

Fig. 7. Deuterium pellets at various stages of formation along the curve shown in Fig. 6.

Fig. 8. Velocity of $6.2-\mathrm{kPa}-\mathrm{I}(47-\mathrm{Torr} \mathrm{l})$ deuterium pellets as a function of hydrogen propellant supply pressure:

Fig. 9. Deuterium pellets with velocities between 1750 and $1790 \mathrm{~m} / \mathrm{s}$.

Fig. 10. A tritium pellet. 